\title{
Экранированные и безэховые камеры для защиты конфиденциальной информации и проведения испытаний на ЭМС
}

\author{
Е. Фёдоров ${ }^{1}$
}

УДК 621.391.825:621.396.6 | ВАК 05.11.01

\begin{abstract}
Ужесточение требований к противодействию радиоэлектронной разведке требует внедрения на промышленных объектах самых передовых технологий, позволяющих обеспечить защиту конфиденциальной информации и выполнения специальных радиотехнических измерений. Группа компаний "МАСКОМ» предлагает ряд эффективных решений в этой области, в частности экранированные и безэховые камеры для создания защищенных помещений и проведения испытаний на ЭМС, средства измерений (в том числе военного назначения) и специализированное ПО для управления ими. Оборудование и оснастка, разработанная на предприятии, отвечают действующим и перспективным требованиям Федеральной службы по техническому и экспортному контролю (ФСТЭК) и ФСБ России. Собственная конструкторская и производственная база ГК "МАСКОМ" позволяет решать комплекс задач, связанных с созданием и оснащением защищенных производственных участков и испытательных лабораторий.
\end{abstract}

ущественное расширение сферы применения электротехнических, электронныхи радиоэлектронных устройств и компонентов в значительной степени повышает опасность нарушений функционирования и повреждений технических средств и систем при воздействии электромагнитных помех. Используемые изделия и компоненты восприимчивы к кондуктивным и излучаемым помехам, электростатическим разрядам, что диктует необходимость проведения испытаний радиоэлектронного оборудования на соответствие стандартам по ЭМС, измерения уровня электромагнитного фона в заданных условиях электромагнитной обстановки. Для этого применяются экранированные камеры, способные предотвратить влияние внешнего электромагнитного излучения. Кроме того, создание экранированных сооружений для защиты технических средств от утечки информации по каналу побочных электромагнитных излучений и наводок - один из наиболее эффективных методов противодействия средствам радиоэлектронной разведки.

При разработке таких проектов необходим комплексный подход, основанный на тщательном анализе исходных данных и требований стандартов. ГК "МАСКОМ»,

ГК «МАСКОМ», директор по маркетингу и рекламе,

fedorov@mascom.ru. имеющая большой опыт проектирования и обслуживания экранированных сооружений, в частности экранированных и безэховых камер, предлагает решения под ключ с учетом полного набора требований заказчика. Группа компаний разрабатывает несколько типов экранированных камер:

- защитные и испытательные экранированные камеры в области радиотехнической безопасности и противодействия иностранным техническим разведкам;

- защитные, испытательные и исследовательские экранированные камеры в области ЭмС и экологической безопасности;

- комбинированные камеры с электромагнитной защитой (до 2-го класса экранирования включительно) и вибро / звукоизоляцией (60 дБ в речевом диапазоне частот).

В соответствии с ГОСТ Р 50414-92 и методиками ФСТЭК России камеры обеспечивают эффективность экранирования на уровне не менее 80 дБ в диапазоне частот от 90 кГц до 40 ГГц и по требованию заказчика могут быть изготовлены любыхгабаритов.

Безэховые камеры (БЭК), созданные на основе экранированных камер, применяют для изучения электромагнитной совместимости технических средств, построения 
диаграмм направленности излучения антенн, диаграмм эффективной площади рассеяния объектов (ЭПр) (рис. 1). Они также используются в процессе контроля на соответствие требованиям различных отраслевых стандартов.

Внутреннее пространство БЭК условно разделено на две зоны:

- безэховую (рабочую зону), в которой устанавливается испытуемый объект;

- излучения, где размещаются передающие устройства.

Измерительное расстояние в БЭК - это расстояние между испытуемым образцом и измерительной антенной. Тихой называется зона, в которой затухание электромагнитных волн аналогично затуханию в свободном пространстве, значения затухания электромагнитных волн в этой зоне не должны отличаться от эталонных значений более чем на \pm 4 дБ.

БЭК подразделяются на полубезэховые и безэховые. В последнем случае стены камеры, пол и потолок полностью покрываются радиопоглощающим материалом (РПМ). Для свободного перемещения персонала в таких камерах создаются помосты из блочных РПМ или используются съемные блоки РПМ. БЭК могут быть выполнены как в модульном цельносварном, так и сборно-разборном исполнении. ГК "МАСКОМ» обеспечивает инженерную подготовку помещения для БЭК, а также температурновлажностный режим для любых условий.

В состав БЭК входят электромагнитный экран с требуемым коэффициентом экранирования и радиопоглощающий материал (РПМ), который монтируется на внутренней поверхности экранированной камеры. Основными параметрами РПМ являются коэффициент затухания (отражения) и рабочий диапазон частот. Дополнительные требования к РПМ: пожароустойчивость, отсутствие вредных выделений, удобство при монтаже и эксплуатации, размеры (форма, вес), возможность

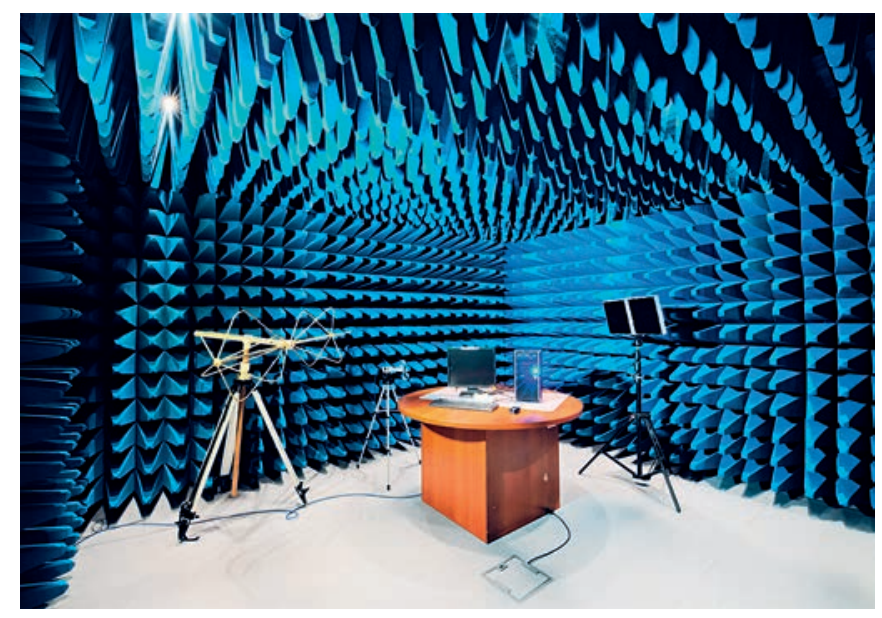

Рис. 1. Измерения в безэховой камере
Таблица 1. Коэффициент отражения по мощности РПМ «ЭРИДАН»

\begin{tabular}{cc} 
Частота & Коэффициент отражения \\
300 МГц & -5 дБ \\
\hline 400 МГц & -15 дБ \\
\hline 600 МГц & -15 дБ \\
\hline 1000 МГц & -25 дБ \\
\hline 1,5 Гц & -30 дБ \\
\hline $3-40$ ГГц & -40 дБ \\
\hline
\end{tabular}

использования в помещениях с определенным классом частоты, стоимость.

ГК "МАСКОМ» поставляет и устанавливает радиопоглощающие материалы объемно-резистивного типа собственного производства. РПМ серии «ЭРИДАН» представляют собой четырехгранную пирамиду, выполненную из полимерных материалов с ультрадисперсным углеродным наполнителем (рис. 2).

Внешние размеры РПМ серии "ЭРИДАН»: $525 \times 175 \times 530$ мм, диапазон частот: от 300 МГц до 40 ГГц. РПМ представляет собой сборную конструкцию, состоящую из блоков размером 525 × 525 мм. Условия эксплуатации: диапазон рабочих температур от 5 до $60^{\circ} \mathrm{C}$, относительная влажность не более 80\%. РПМ «ЭРИДАН» изготовлен из самозатухающего материала (группа горючести Гз). Значения коэффициента отражения по мощности при падении электромагнитной волны по нормали к изделию в зависимости от частоты представлены в табл. 1.

Радиопоглощающие покрытия изготавливаются из магнитомягких материалов, которые эффективны на частотах от десятков мегагерц до единиц гигагерц. Эти

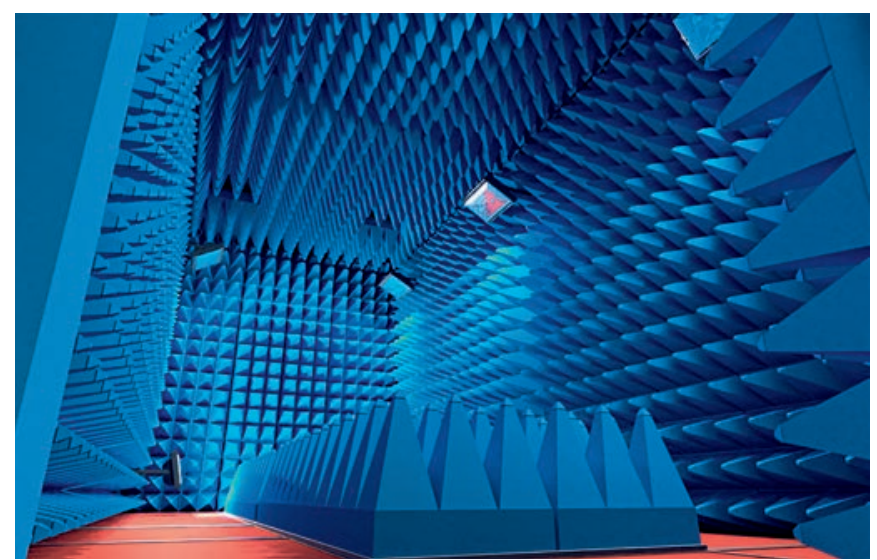

Рис. 2. Стены, потолок и пол безэховой камеры покрыты пирамидальным РПМ «ЭРИДАН-МР530" 
материалы конструктивно могут быть выполнены в виде ферритовых пластин или сборных панелей (ферритовых пластин, наклеенных на диэлектрик). Кроме того, в качестве магнитомягких могут применяться композиционные материалы в виде ферритового порошка или карбонильного железа в полимерной связке (бруски на основе эпоксидной смолы в виде гибких листов, например из резины).

Преимуществами магнитомягких материалов являются высокая эффективность поглощения на частотах от 20 до 1000 МГц, небольшая толщина покрытия, высокая механическая прочность, пожароустойчивость, отсутствие вредных выделений. Кроме того, они хорошо подходят для монтажа на пол камеры. К их недостаткам относятся низкая эффективность в ВЧ-диапазоне, большой удельный вес, высокая стоимость, чувствительность к углам падения волн. Кроме того, композиции с использованием полимерных наполнителей чувствительны К высоким температурам.

Для обеспечения радиопоглощения в широком диапазоне частот (от 20 МГц до 100 ГГц) в одной конструкции сочетают магнитомягкие и объемно-резистивные/радиорассеивающие материалы, эффективные на частоте более 1 ГГц. Обычно магнитомягкие материалы выполняются в виде пластин или панелей, на которые крепятся объемно-резистивные или радиорассеивающие материалы. Наряду с широким диапазоном частот преимуществом сборных конструкций является их

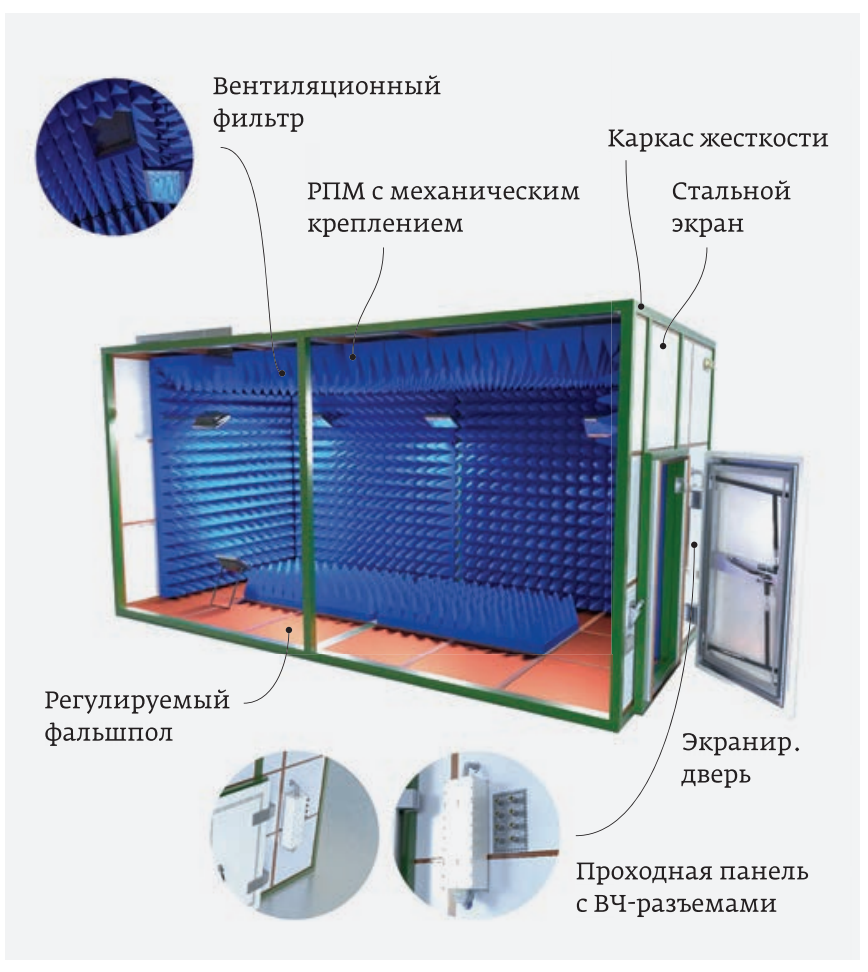

Рис. 3. Безэховая камера типа МК-БэК-3 или МК-БэК-10 компактность, особенно в случае применения пирамидальных конструкций.

ГК "МАСКОМ» выпускает две модификации безэховых экранированных камер - МК-БЭК-3 и МК-БЭК-10.

МК-БЭК-3 - безэховая камера с 3-метровым измерительным расстоянием, предназначенная для проведения испытаний в соответствии с НМД ФСБ и ФСТЭК России (рис. 3). Диапазон частот составляет от 30 МГц до 40 ГГц, площадь тихой зоны-1,5×1,5 м.

Габариты экранированного корпуса МК-БЭК-3 9,15×7,10×6 м (внешние размеры, включая несущую раму). В базовую комплектацию входит экранированная дверь размером $900 \times 2000$ мм.

В МК-БЭК-3 применяется комбинированное решение для радиопоглощающего материала. Стены, пол, потолок камеры покрыты ферритовыми плитками $100 \times 100 \times 6$ мм, рассчитанными на диапазон частот от 30 до 1000 МГц, их характеристики поглощения от -15 до -25 дБ. Для частотного диапазона от 1000 МГц до 18 (40) ГГц применены пирамидальные поглотители "ЭРИДАН-МР530», которыми покрыты стены и потолок. На полу размещаются съемные блоки с пирамидальными поглотителями "ЭРИДАН-МР530", их характеристики поглощения От -50 до -40 дБ.

МК-БЭК-3 оснащена несколькими системами фильтрации: сети электропитания (два фильтра на 16 и 40 A), приточно-вытяжной вентиляции и слаботочной фильтрации.

В состав камеры входят проходная панель с ВЧ-разъемами (три разъема N-типа и столько же разъемов типа SMA), системы электроснабжения, вентиляции, слаботочные системы (два аналоговых датчика пожарной сигнализации), а также система оптоволоконных вводов.

В качестве опций камеры могут комплектоваться поворотным столом; автоматической антенной мачтой; контроллерами интерфейса GPIB; дополнительными фильтрами и специальными разъемами; системами приточно-вытяжной вентиляции, кондиционирования, видеонаблюдения, внутренней связи / аудиосистемами, сигнализации о пожарной тревоге.

Еще одна модель безэховой камеры ГК «МАСКОМ»МК-БЭК-10. Это полностью отвечающая стандартам безэховая камера с измерительным расстоянием 3 и 10 м, диапазон частот от 30 МГц до 40 ГГц, площадь тихой зоны $5 \times 5 \mathrm{M}$.

Камера МК-БЭК-10 с экранированным корпусом габаритами 21,7×13,8×8,6 м и экранированной дверью оснащена теми же системами фильтрации, электроснабжения, вентиляции и другими системами, что и МК-БЭК-З. Опционально может комплектоваться поворотным столом (любого диаметра, для различных нагрузок), автоматической антенной-мачтой (сканирование высотой от 1 до 4 м, изменение поляризации), контроллерами 


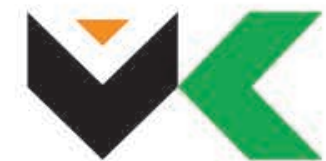

MAСK

ГРУППАКОМПАНИЙ

ГРУППА КОМПАНИЙ МАСКОМ 121596, МОСКВА,

УЛ. ГОРБУНОВА, Д. 2, СТР. 5

+7 (495) 136-40-10

+7 (495) 136-40-20
КОМПЛЕКСНЫЙ

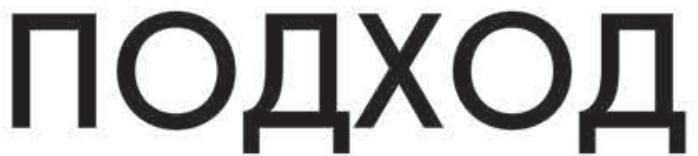

К БЕЗОПАСНОСТИ
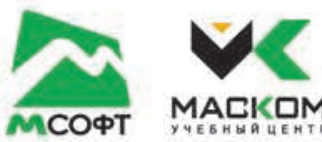

MACKOM MACIKOM MACIKOM

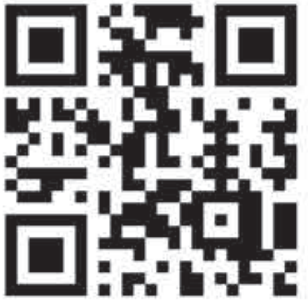

WWW.MASCOM.RU MASCOM@MASCOM.RU

\section{ТЕХНОЛОГИИ ЗАЩИТЫ ИНФОРМАЦИИ \\ И КОНТРОЛЯ ЗАЩИЩЕННОСТИ}

$(((9)))$

РАДИОТЕХНИЧЕСКАЯ БЕЗОПАСНОСТЬ

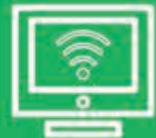

ИНФОРМАЦИОННАЯ ЕЕЗОПАСНОСТЬ

И ТЕЛЕКОММУНИКАЦИИ

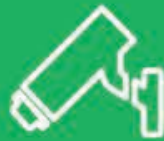

ИНЖЕНЕРНО-ТЕХНИЧЕСКИЕ СРЕДСТВА

ОХРАнЫ

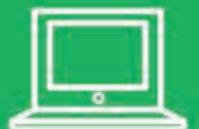

\section{РАЗРАБОТКА СПЕЦИАЛИЗИРОВАННОГО \\ ПРОГРАММНОГО ОБЕСПЕЧЕНИЯ}

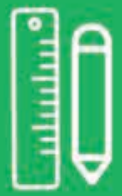

ОБУЧЕНИЕ И ПОВЫШЕНИЕ

КВАЛИФИКАЦИИ СПЕЦИАЛИСТОВ

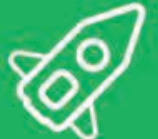

КАПИТАЛЬНОЕ СТРОИТЕЛЬСТВО

СПЕЦИАЛЬНЫХ ОБЬЕКТОВ

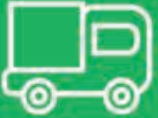

TPAHCIOPTHAЯ EEЗOกACHOCTЬ 


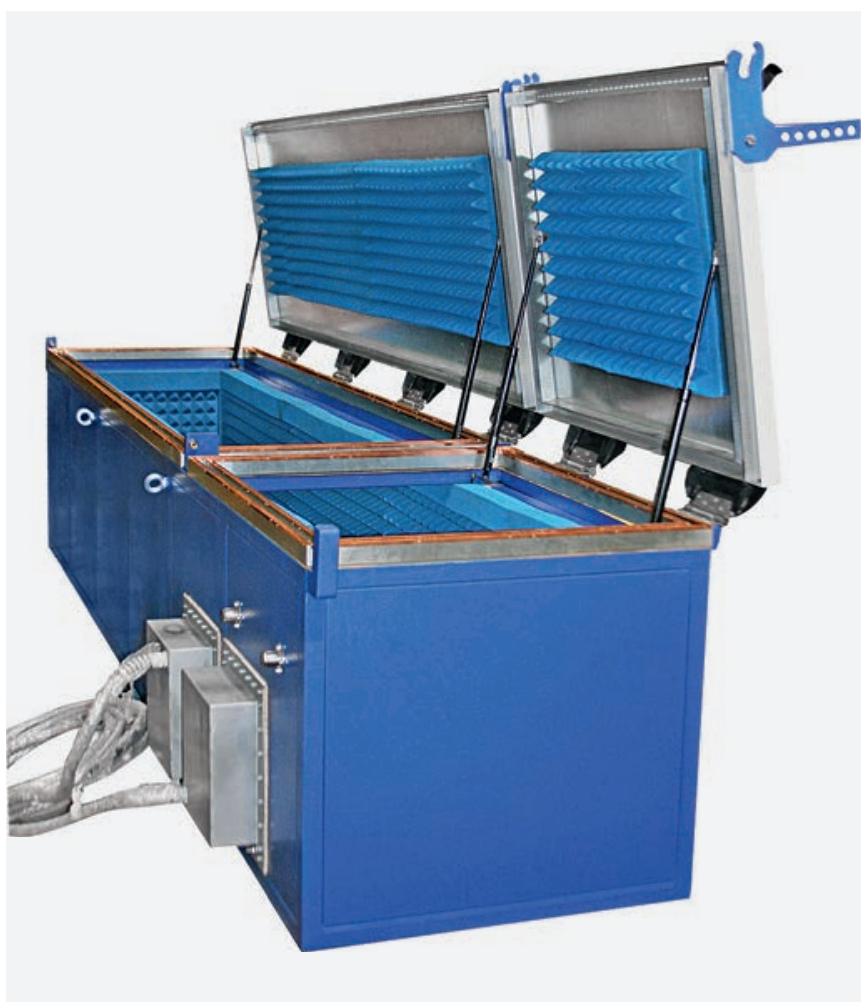

Рис. 4. Экранированный контейнер

интерфейса GPIB (для дистанционного управления позиционерами), дополнительными фильтрами мощности, специальными разъемами, другими системами.

Камеры МК-БЭК-3 и МК-БЭК-10 предназначены для проведения испытаний на эффективность экранирования, измерений коэффициентов затухания, неоднородности поля, КСВ, испытаний на соответствие стандарту ГОСТ Р 50414-92. На экранированный корпус, экранированную дверь и системы фильтрации предоставляется гарантия 36 месяцев.

Для безэховых камер и других экранированных объектов ГК «МАСКОМ» разрабатывает и производит экранированные двери и ворота любых размеров, классов согласно требованиям заказчика. Эффективность экранирования

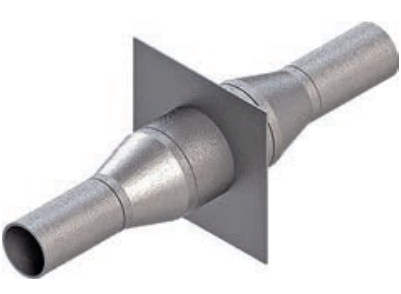

Рис. 5. Трубопроводный фильтр серии «КBAPTET-H»

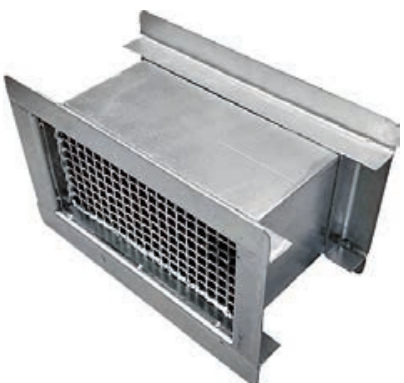

Рис. 6. Воздуховодный фильтр серии «КВАРТЕТ-О»

дверей в соответствии с ГОСТ составляет не менее 80 дБ в диапазоне частот от 0,15 МГц до 40 ГГц.

На двери можно устанавливать механизмы автозапирания, защелки и механизмы аварийного открывания. Кроме того, дверь может быть снабжена дополнительным стационарным и передвижным пандусами для транспортировки тяжелого оборудования, а также электрической системой отпирания / запирания.

Наряду с безэховыми камерами ГК «МАСКОМ» выпускает экранированные шкафы, боксы и контейнеры для хранения специальных технических средств, размещения вычислительной техники для обработки сведений, составляющих государственную тайну (рис. 4). Экранированные шкафы рассчитаны на диапазон частот от 0,01 МГц до 10 ГГц, коэффициент экранирования составляет не менее 60 дБ во всем диапазоне.

Стандартные габаритные размеры экранированных шкафов $1150 \times 950 \times 300$ мм, по требованию заказчика возможно производство экранированных шкафов любых размеров. Экранированные боксы/контейнеры предназначены для испытания различного оборудования на ЭМС при пониженных внешних промышленных радиошумах, а также для защиты информации, содержащей государственную тайну, при работе данного оборудования.

Безэховые камеры комплектуются различными фильтрами и проходными компонентами, которые необходимы для ввода инженерных коммуникаций внутрь ЭК и БЭК с сохранением характеристик экранирования во всем диапазоне частот. Водопроводные фильтры предназначены для подачи в экранированные сооружения жидкостей и газов (рис. 5). Они рассчитаны на диапазон частот от 10 кГц до 40 ГГц, затухание по магнитной и электрической составляющей - не менее 80 дБ.

Воздушные фильтры (рис. 6) для воздухообмена экранированного сооружения с внешней средой в целях жизнеобеспечения обслуживающего персонала и дымоудаления рассчитаны на размеры воздуховодов от $100 \times 100$ мм до $1000 \times 1000$ мм. Устройства обеспечивают затухание электромагнитной энергии до 100 дБ в диапазоне частот от 0 до 100 ГГц.

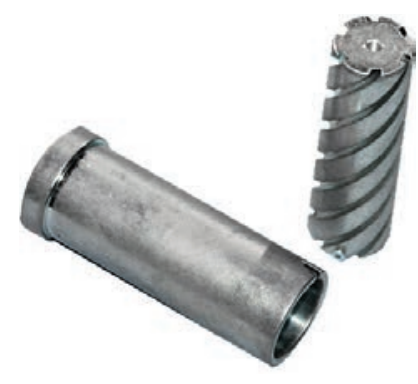

Рис. 7. Фильтр оптический серии "КВАРТЕТ-С"

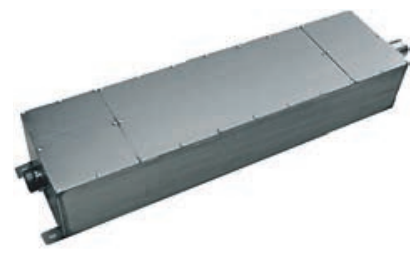

Рис. 8. Фильтр помехоподавляющий серии «КВАРТЕT-E» 


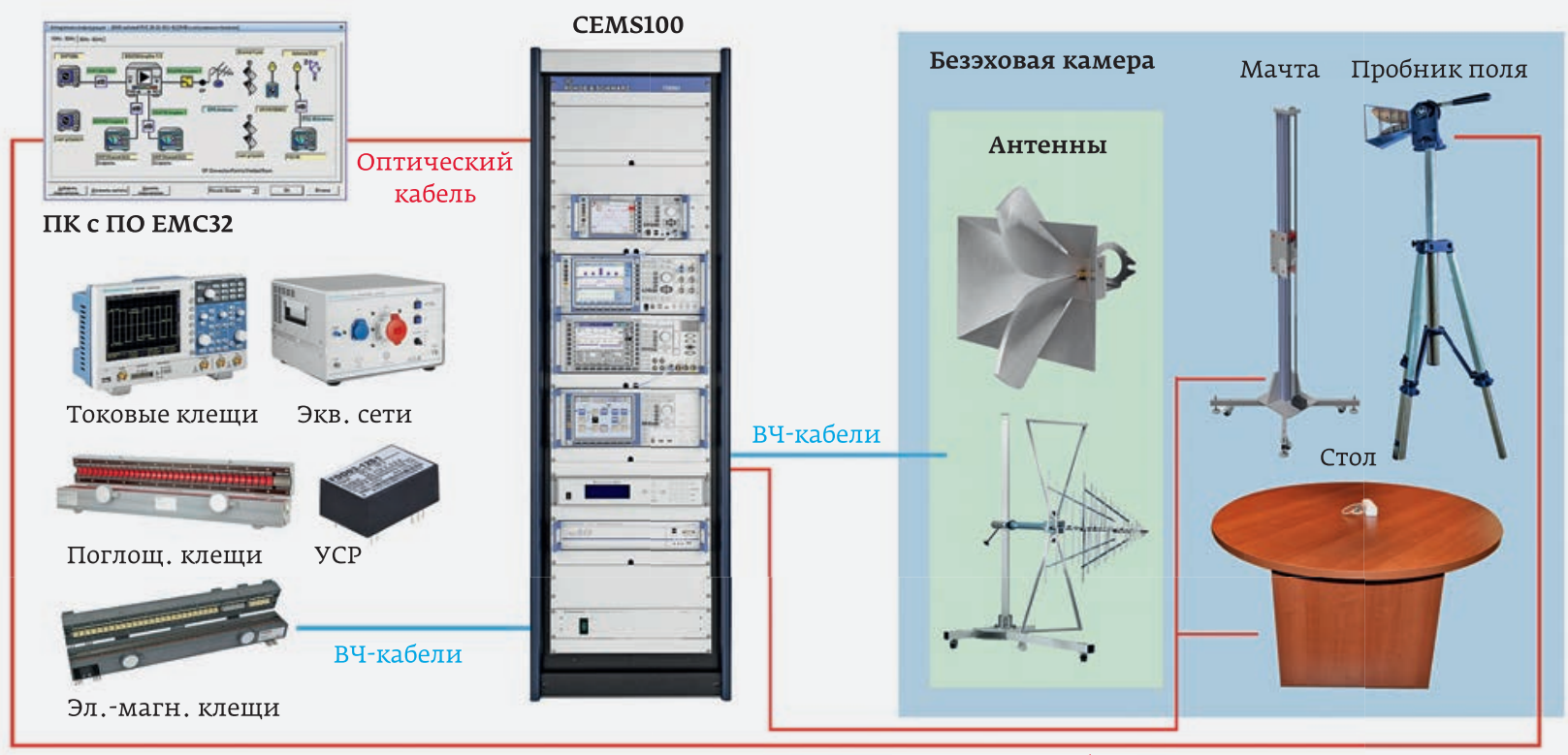

Оптические кабели

Рис. 9. Модульная система для испытаний на ЭМС

Оптические фильтры (рис. 7) для ввода оптоволоконных линий внутрь БЭК содержат от шести оптоволоконных линий, эффективность экранирования составляет не менее 80 дБ в диапазоне частот от 10 кГц до 40 ГГц.

Помехоподавляющие фильтры (рис. 8) предназначены для защиты средств вычислительной техники и иных технических средств от утечки информации в результате наводок информативных сигналов в однофазных (трехфазных) сетях электропитания. Нагрузочная способность до 200 А (зависит от модификации).

ГК “МАСКОМ» проектирует и поставляет системы для проведения испытаний на помехоустойчивость и измерений помехоэмиссии. Комплект оборудования системы для испытаний проектируется исходя из целей и задач заказчика, типов и видов испытаний, требований стандартов, на соответствие которым проводятся испытания, а также специальных технических требований. Построение системы для испытаний на ЭМС (рис. 9) по модульному принципу обеспечивает возможность модернизации, расширения функционала, организации рабочих мест для инженерного персонала.

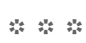

ГК «МАСКОМ» предлагает комплексные решения для создания и оснащения защитных экранированных сооружений, а также испытательных центров и лабораторий для проведения испытаний на ЭМС и помехоустойчивость. По требованиям заказчика к испытательному оборудованию прилагаются заключение по итогам специальной проверки и протокол по результатам специальных исследований с условиями размещения и эксплуатации в случае установки в помещениях, предусмотренных для ведения конфиденциальных переговоров.

В зависимости от габаритов объекта, диапазона частот и методов испытаний экранированные сооружения могут достигать размеров в несколько десятков метров. Для построения таких сложных объектов требуется выполнение проектно-конструкторских работ по архитектурным и планировочным решениям, системам вентиляции и кондиционирования, освещения, электропитания, водяного охлаждения и т.д. ГК «МАСКОМ» выполняет весь комплекс работ под ключ.

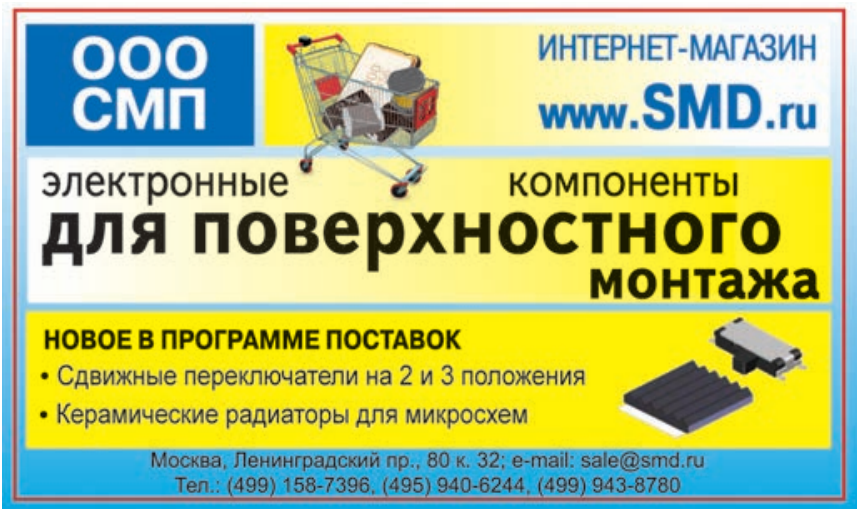




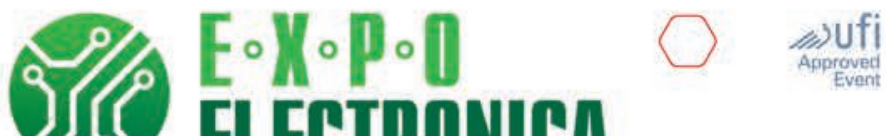

a Hyve event
Самая крупная в России выставка электронных компонентов, модулей и комплектующих

\section{4-16 апреля 2020}

Москва, МВЦ «Крокус Экспо»

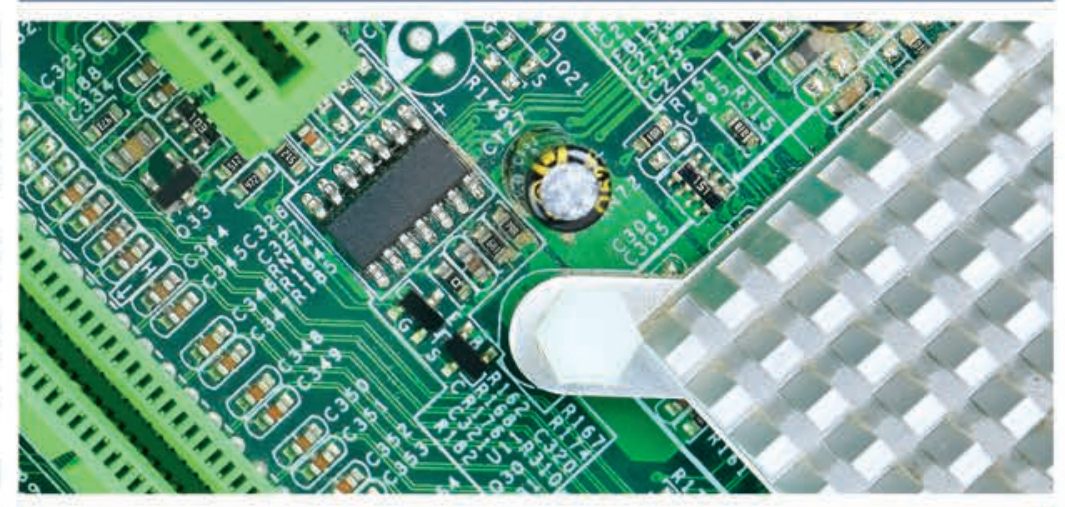

Специальные темы:

\section{$5 \mathbf{G}$

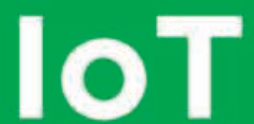 \\ Al}

Приглашаем к участию

производителей и поставщиков ЭКБ,

комплектующих и ПО для:

- Базовых станций для 56

- Ядер сети

- Транспортных сетей

- Приложений для 5G

- Абонентских устройств

- Систем Іот и искусственного интеллекта

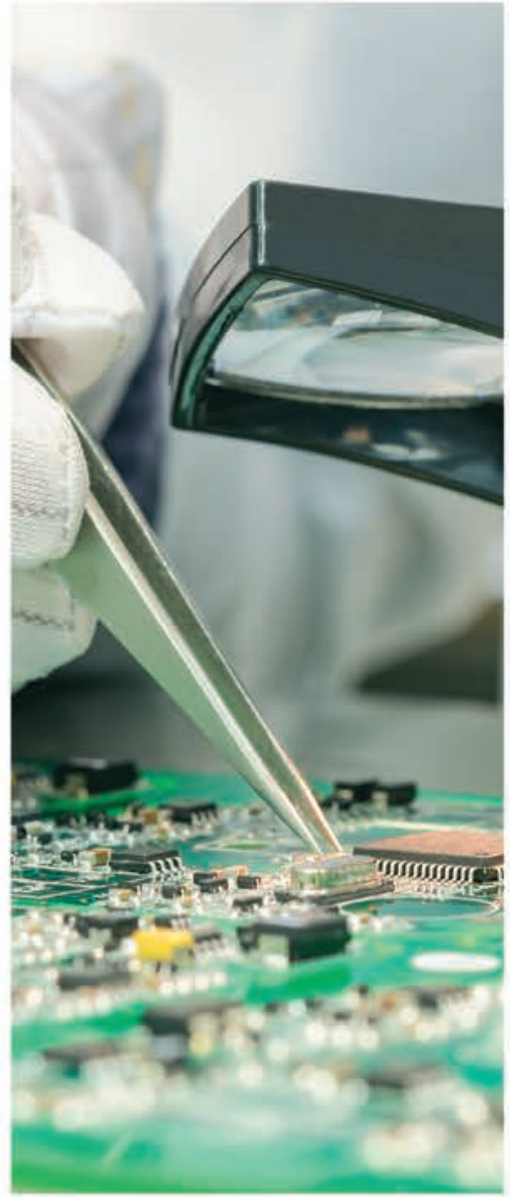

\section{Ваш}

компонент

ycnexa!

expoelectronica.ru
Hyve

+7 (499) 750-08-28 electron@hyve.group www.hyve.group
Совместно с выставкой

(1) ELERTRON 